\title{
Exploring the Relationship Between Covert Narcissism and Amorality: The Mediating Influences of Self-efficacy and Psychological Entitlement
}

\author{
Curtis F. Matherne, III \\ University of Louisiana at Lafayette \\ Keith R. Credo \\ University of Louisiana at Lafayette \\ Eric B. Gresch \\ Georgia Gwinnett College \\ Patricia A. Lanier \\ University of Louisiana at Lafayette
}

\begin{abstract}
Narcissism, as a personality construct, has attracted attention from countless scholars across multiple disciplines. It has been suggested that two forms of narcissism exist (Wink, 1991) and research has supported the delineation of overt (grandiose) and covert (hypersensitive) narcissism (Dickinson \& Pincus, 2003; Gabbard, 2009; Luchner, Houston, Walker, \& Houston, 2011). To date, most of the research devoted to narcissism has been focused on the overt rather than the covert form (Cain, Pincus, \& Ansell, 2008). Further, researchers propose that a decreased level of meaningful relational interactions among narcissists may result in a higher propensity for amoral behaviors. Thus, to extend the research the current study explores the influence of several mediating variables on the relationship between covert narcissism and amorality. The current study found a negative relationship between covert narcissism and self-efficacy as well as an anticipated positive relationship between covert narcissism and psychological entitlement. It was also observed that self-efficacy and psychological entitlement did partially mediate the relationship between covert narcissism and higher amorality, supporting the study's predictions.
\end{abstract}

Keywords: Narcissism, Amorality, Self-efficacy, Entitlement

\section{INTRODUCTION}

Narcissism, as a personality construct, has attracted attention from countless scholars across multiple disciplines. Current research suggests that not only is narcissism becoming more prevalent in American culture (Miller, et al., 2015), it may also be more prominent among the Millennial generation (Credo, Lanier, Matherne, \& Cox, 2016). Furthermore, narcissism expressed as entitlement and self-absorption are generally conceptualized in the context of overt narcissism. Narcissists are often characterized as 
being more likely to exhibit entitled and grandiose behaviors (Shijiang, Fang, Yan, Fengxiang, \& Xinting, 2016) consistent with overt narcissism, but less extant research has explore covert narcissism, which may relate as much or more to traits such as amorality. This study explores the relationships of covert narcissism with self-efficacy, entitlement and amorality, to better understand the nature and resulting effects of covert narcissism. Specifically, we extend prior research to assess the mediating impact of not only self-efficacy, but also psychological entitlement on amorality. In doing so, this study seeks to provide a deeper understanding of the intricacies of narcissism by expanding the domain of covert narcissism to include the inter-relationships with amorality, psychological entitlement, and self-efficacy.

\section{Narcissism}

Narcissism, as a personality trait, is generally characterized by inflated self-perceptions, feelings of superiority, egotism, and self-promotion. (e.g. Campbell, Bosson, Goheen, Lakey, \& Kernis, 2007; Twenge, Konrath, Foster, Campbell, \& Bushman, 2008). It has been suggested that two forms of narcissism exist (Wink, 1991) and research has supported the delineation of overt (grandiose) and covert (hypersensitive) narcissism (Dickinson \& Pincus, 2003; Gabbard, 2009; Luchner, Houston, Walker, \& Houston, 2011). These two types of narcissism are differentiated by the nature of their manifestation. Overt narcissism is typically displayed through egotism, self-esteem, assertiveness, and grandiosity; whereas covert narcissism is characterized more through vulnerability, deflated self-image, and hypersensitivity (Wink, 1991). To date, most of the research devoted to narcissism has been focused on the overt rather than the covert form (Cain, Pincus, \& Ansell, 2008). Thus, the current study seeks to extend research by examining behaviors that may be linked to this underexplored form of narcissism, covert or hypersensitive narcissism.

\section{Covert Narcissism and Amorality}

Narcissists tend to pursue power and self-promotion which may lead to a preoccupation with success at any cost and a disregard for ethical implications (Clark, Lelchook, \& Taylor, 2010). This focus on success at any cost can result in negative implications for any sort of moral code that might prevent or slow the narcissist's quest for self-promotion and success. This lack of adherence to a moral code may manifest itself as amoral behavior. Amorality represents a willingness to selectively disregard moral standards when an opportunity to benefit oneself is presented (Dahling, Whitaker, \& Levy, 2009). Often contrived as a component of Machiavellianism (Dahling, et al., 2009), amorality has shown positive correlations with narcissism (Paulhus \& Williams, 2002). "To varying degrees, both narcissism and Machiavellianism share a socially malevolent character with behavior tendencies toward self-promotion, emotional coldness, duplicity, and aggressiveness" (Paulhus \& Williams, 2002, p. 557).

A generalized tenet of morality is empathy one has for others, as empathy is an emotional process with significant implications for moral behavior (Tangney, Stuewig, \& Mashek, 2007). Multiple recent studies have observed a negatively correlated association between narcissism and empathy, albeit weak results (e.g. Giammarco \& Vernon, 2014; Jonason \& Krause, 2013; Wai \& Tiliopoulos, 2012). These weak and negative study results may be descriptive of the specific way in which narcissists tend to express empathy. Specifically, narcissists' focus on self-promotion and success at any cost does not preclude elements of narcissism and empathy; rather, narcissists will simply be less consistent in display of compassion and empathy, particularly in situations when these conflict with the narcissist's success or ability to self-promote. This low occurrence of displays of empathy may be indicative of amoral behaviors Consistent with this reasoning, Miller, Smart, \& Rechner (2015) found amorality to have a strong, negative relationship to empathy.

Additionally, Campbell et al. (2007) note that narcissists tend to have less than average amounts interpersonal relationships and intimacy. As a result, narcissists may be less likely to interact on a meaningful level with the individuals whom their decisions affect. When individuals are unaware of how their actions affect others, amoral behaviors may increase, consistent with Rest, Narvaez, Bebeau, and Thoma's (1999) model of morality. They recognize moral sensitivity as a key component for moral behavior, as moral sensitivity is one's ability to evaluate a situation for its moral implications and the 
ability to understand how one's actions will affect others. Thus, a decreased level of meaningful relational interactions among narcissists may result in a higher propensity for amoral behaviors.

\section{Self-efficacy and Psychological Entitlement as Mediators}

Self-efficacy can be characterized as a domain of the self-concept that relates specifically to one's perceived ability to perform tasks (Bandura, 1986). Judge, LePine and Rich (2006) found that self-ratings of leadership ability was significantly positively related to narcissism, as inflated perceptions of the self could logically extend to the perception of one's ability to influence others. Additionally, multiple researchers have observed that narcissists consistently rate themselves as better than average on efficacy related characteristics such as task performance and intelligence, (Campbell, Rudich, \& Sedikides, 2002; Grijalva \& Zhang, 2016). Maynard, Brondolo, Connelly, and Sauer (2015) found that the traits of narcissism were positively correlated with perceptions of over qualification. Simply, levels of selfefficacy and narcissism share a great degree of communality. However, these prior works reflect the connection of one's appraisal of self as ascribed to overt narcissism.

It has been presented that regardless of the explicit persona offered, narcissists tend to embody a heightened degree of internal self-loathing (Campbell et al., 2007). In support of this notion, covert narcissism has just recently been empirically linked to self-efficacy, representing a negative association (Brookes, 2015). Similarly, those with lower levels of self-efficacy may perceive the world around as a more, threatening, hostile, and stressful place. Borrowing from the adage, "desperate times call for desperate measures" individuals in a loathing state may be more likely to act based on elevated survivalist fears, resulting in a decreased level of importance based on moral codes. Individuals with low selfefficacy tend to focus on their coping deficiencies and amplify the severity of possible threats (Bandura, 1997). We contend that when differentiating the types of narcissism, self-efficacy has the opposite relationship with each.

Psychological entitlement is generally understood as one's sense of being more deserving than others (Campbell, Bonacci, Shelton, Exline, \& Bushman, 2004). Individuals high in psychological entitlement tend to hold increased expectations for preferential treatment (Harvey \& Harris, 2010). Past research had originally classified entitlement as a facet of narcissism, however recent research has established psychological entitlement as a stand-alone construct, empirically distinct from narcissism (Campbell et al., 2004). As prior studies have linked narcissistic traits and various forms of entitlement (e.g. Chowning \& Campbell, 2009; Lessard, Greenberger, Chen, \& Farruggia, 2011; Turnipseed \& Cohen, 2015), we expect to observe similar positive relationships. Past research has also suggested entitlement may result in an increase in amoral behavior. Miller (2015) found entitlement to positively predict organizational deviant behaviors such as making unauthorized use of organizational property, lying about the number of hours worked, and purposely ignoring supervisor's instructions. Indeed, as entitlement increases, so does one's expectation of preferential treatment. This, by definition, involves a disregard of fairness or equity to some degree. Thus, we expect one who disregards moral tenets of equity and fairness to engage in an increased level of amoral behavior.

To conclude, no previous research has yet investigated the mediating impact of self-efficacy and entitlement on the relationship of narcissism and amorality. Based on the previous research and theory above, the following two hypotheses are proposed: (1) Self-efficacy will mediate the relationship between narcissism and amorality, such that lower levels of self-efficacy increase the influence of narcissism on amorality. (2) Psychological entitlement will mediate the relationship between narcissism and amorality, such that higher levels of psychological entitlement increase the influence of narcissism on amorality.

\section{METHODS}

\section{Participants and Procedure}

A total of 309 working adults (158 female, and 151 male) ranging in age from 19 to 48 years $(\mathrm{M}=$ $23, \mathrm{SD}=3.01)$ participated in the study. No significant differences were observed for age or gender effects, so they were not incorporated into the subsequent testing. Volunteers were recruited from a 
student sample at a large public university in the Southeast United States via an online survey instrument. Participants received extra credit for voluntarily participating in the survey.

\section{Measures}

Covert Narcissism

A ten-item scale was used to measure Narcissism. The scale used was Hendin and Cheek's Hypersensitive Narcissism scale (1997), designed to assess overestimation of one's own abilities and excessive self-admiration. Sample items include "I dislike sharing the credit of an achievement with others" and "I am secretly 'put out' or annoyed when others come to me with their troubles, asking me for my time and sympathy". Responses were recorded using a five-point Likert-type response format ranging from "strongly disagree" to "strongly agree". Coefficient $\alpha$ for the ten-item scale was .74.

\section{Amorality}

A five-item measure developed by Dahling et al., (2009) was used to measure Amorality. The construct represents an overall indifference to a moral perspective or without a clear definition of right or wrong. Sample items include "I am willing to be unethical if I believe it will help me succeed" and "I am willing to sabotage the efforts of other people if they threaten my own goals." Responses were recorded using a five-point Likert-type response format ranging from "strongly disagree" to "strongly agree". Coefficient $\alpha$ for the five-item scale was .89.

\section{Self-efficacy}

An eight-item measure developed by Chen, Gully, and Eden (2001) was used to measure selfefficacy. The construct represents one's belief in their own capability to meet the demands of any given situation. Sample items include "I will be able to achieve most of the goals that I have set for myself" and "I believe I can succeed at most any endeavor to which I set my mind." Responses were recorded using a five-point Likert-type response format ranging from "strongly disagree" to "strongly agree". Coefficient $\alpha$ for the eight-item scale was .89.

\section{Psychological Entitlement}

An eight-item scale was used to measure Psychological Entitlement. Items were taken from the Psychological Entitlement Scale developed by Campbell, et al (2004), designed to measure entitlement across situations. Psychological Entitlement assesses generalized feelings of being deserving. Sample items include "If I were on the Titanic, I would deserve to be the first lifeboat" and "People like me deserve a break every now and then". Responses were recorded using a five-point Likert-type response format ranging from "strongly disagree" to "strongly agree". Coefficient $\alpha$ for the eight-item scale was .83 .

\section{Procedure}

All participants completed a questionnaire via an online survey program containing demographic questions and measures to assess participants' feelings about their organizations, work styles, and personalities in the context of a course-specific project. While 330 surveys were started on the survey platform, 309 complete responses were obtained. Surveys took about 10 minutes to complete. Responses to all scales included in the study were recorded using a five-point Likert-type response format ranging from "strongly disagree" to "strongly agree".

\section{Data Analysis}

Structural equation modeling (SEM) was used to explore how self-efficacy influenced the relationship between narcissism and both entitlement and amorality. Anderson and Gerbing's (1988) technique was used to test mediation. The first step of this two-step procedure involved assessing the measurement model to be sure each latent variable was represented by its indicators. Assuming the measurement model yields satisfactory results, the structural model is then tested. Maximum likelihood 
estimation is calculated for the structural model using AMOS version 18.0. To minimize inflated measurement error resulting from multiple scale items, two item parcels were created for each factor of narcissism, self-efficacy, amorality, and entitlement. An item-to-construct balance approach was used to determine item placement into parcels (Kong, Wang, \& Zhao, 2014; Little, Cunningham, Shahar, \& Widaman, 2002). Multiple goodness-of-fit indices were used to determine model fit adequacy, including chi square statistics, root-mean-square error of approximation (RMSEA) of .06 or less, standardized rootmean-square-residual (SRMS) of .09 or less, and comparative fit index (CFI) of .90 or greater, with .95 or greater preferred (Hu \& Bentler, 1999).

\section{RESULTS}

\section{Preliminary Analysis}

Table 1 includes means, standard deviations, reliability estimates (Cronbach's alpha), and correlations for all measures. All measures were significantly correlated to at least $\mathrm{p}>.01$.

\section{TABLE 1}

\section{MEAN, STANDARD DEVIATION, RELIABILITIES, AND INTERCORRELATIONS AMONG STUDY MEASURES}

\begin{tabular}{lllllll}
\hline & Mean & SD & $\alpha$ & 1 & 2 & 3 \\
\hline 1. Narcissism & 2.88 & .69 & .74 & - & - & - \\
2. Self-efficacy & 3.11 & .63 & .89 & $-.21^{* *}$ & - & - \\
3. Entitlement & 2.70 & .65 & .83 & $.23^{* *}$ & $.15^{*}$ & - \\
4. Amorality & 1.71 & .82 & .89 & $.38^{* *}$ & $-.25^{* *}$ & $.19^{* *}$ \\
\hline${ }^{*}<.05$ & & & & & & \\
$* * p<.01$ & & & & & &
\end{tabular}

\section{Measurement Model}

The measurement model includes four latent factors (narcissism, self-efficacy, entitlement, and amorality) and 8 observed variables. The measurement model showed excellent fit characteristics, including $\chi 2=16.17, \mathrm{df}=14, \mathrm{RMSEA}=.035, \mathrm{SRMR}=.026, \mathrm{CFI}=993$. Factor loadings for indicators onto latent variables were all acceptable, suggesting that indicators accurately represented their latent factors.

\section{Structural Model}

Multiple alternative models were tested to determine if the proposed theoretical model was the best fit. Table 2 shows the fit indices of four alternative models. First, a partially mediated model was tested with self-efficacy and entitlement as partial mediators between narcissism and amorality. The model showed excellent fit characteristics, including $\chi 2=19.41$, df $=15$, RMSEA $=.035$, PCLOSE $=.686$, $\mathrm{SRMR}=.054, \mathrm{CFI}=.985$. Path coefficients between all model variables were significant at the $\mathrm{p}<.001$ level, except for path coefficients from self-efficacy to entitlement, which was significant at the $\mathrm{p}<.001$ level and self- efficacy to amorality, which was significant at the $\mathrm{p}<.005$ level. Although model fit was more than adequate for the first model, alternative models were tested to ensure the best fit to the data. The first alternative model tested only included self-efficacy, not entitlement, as a mediator between narcissism and amorality. Although Model 2 was more parsimonious, it did not fit the data as well as Model 1: $\chi 2=26.88, \mathrm{df}=16, \mathrm{RMSEA}=.053, \mathrm{PCLOSE}=.397, \mathrm{SRMR}=.062, \mathrm{CFI}=.963$. Next, an alternative model was tested which included self-efficacy as a mediator only between narcissism and entitlement, not narcissism and amorality. Although Model 3 was also more parsimonious, it did not fit the data as well as Model 1: $\chi 2=26.45, \mathrm{df}=16, \mathrm{RMSEA}=.052, \mathrm{PCLOSE}=.417, \mathrm{SRMR}=.069, \mathrm{CFI}=$ 964. Finally, a model was tested in which neither self-efficacy nor narcissism was a mediator for amorality. Although model 4 was the most parsimonious of all models tested, Model 1 still proved to be 
the best fit for the data: $\chi 2=19.41, \mathrm{df}=15, \mathrm{RMSEA}=.035, \mathrm{PCLOSE}=.686, \mathrm{SRMR}=.054, \mathrm{CFI}=.985$. Thus, we concluded that Model 1 was the best model for the data. The direct effect of narcissism on amorality was significant, so self-efficacy and entitlement were partial mediators of amorality.

Bootstrapping procedures were used in AMOS to further examine mediation effects. 5000 bootstrapping samples were generated by random sampling of the original 309 data points. Mediation effects of self-efficacy on the relationship between narcissism and entitlement as well as narcissism and amorality are shown in Table 3 . In both cases, zero was excluded from $95 \%$ confidence interval ranges, indicating a significant indirect effect. Thus, bootstrapping analyses indicated that self-efficacy and entitlement mediate the relationship between narcissism and amorality (Fig. 1).

TABLE 2

FIT INDICES AMONG ALTERNATIVE MODELS

\begin{tabular}{lllllllll}
\hline & $\chi^{2}$ & df & $\chi 2 /$ df & RMSEA & SRMR & CFI & AIC & ECVI \\
\hline Model 1 & $\mathbf{1 9 . 4 1}$ & $\mathbf{1 5}$ & $\mathbf{1 . 2 4 9}$ & $\mathbf{. 0 3 5}$ & $\mathbf{. 0 5 4}$ & $\mathbf{. 9 8 5}$ & $\mathbf{6 1 . 4 1 2}$ & $\mathbf{. 2 5 8}$ \\
Model 2 & 26.88 & 16 & 1.680 & .053 & .062 & .963 & 66.884 & .281 \\
Model 3 & 26.45 & 16 & 1.653 & .052 & .069 & .964 & 66.445 & .279 \\
Model 4 & 35.59 & 17 & 2.093 & .068 & .078 & .936 & 73.585 & .309
\end{tabular}

Note: $\mathrm{N}=309$, RMSEA $=$ root mean square error of approximation; SRMR = standardized root-mean-square residual; $\mathrm{CFI}=$ comparative fit index; AIC $=$ Akaike information criteria; and $\mathrm{ECVI}=$ expected cross validation index. Model 1 was superior to alternative models.

TABLE 3

BOOTSTRAPPING INDIRECT EFFECTS AND 95\% CONFIDENCE INTERVALS (CI) FOR THE MEDIATION MODEL

\begin{tabular}{llll}
\hline & & & \\
\cline { 3 - 4 } Model Pathways & Point & C5 CI & \\
\cline { 3 - 4 } Narcissism $\rightarrow$ Entitlement $\rightarrow$ Amorality & Estimates & Lower & Upper \\
Narcissism $\rightarrow$ Self Efficacy $\rightarrow$ Amorality & .09 & .04 & .19 \\
& -.11 & -.27 & -.05 \\
\hline
\end{tabular}

FIGURE 1

THE STRUCTURAL EQUATION MODEL REGARDING THE MEDIATING EFFECTS OF SELF-EFFICACY AND PSYCHOLOGICAL ENTITLEMENT ON THE RELATIONSHIP BETWEEN COVERT NARCISSISM AND AMORALITY

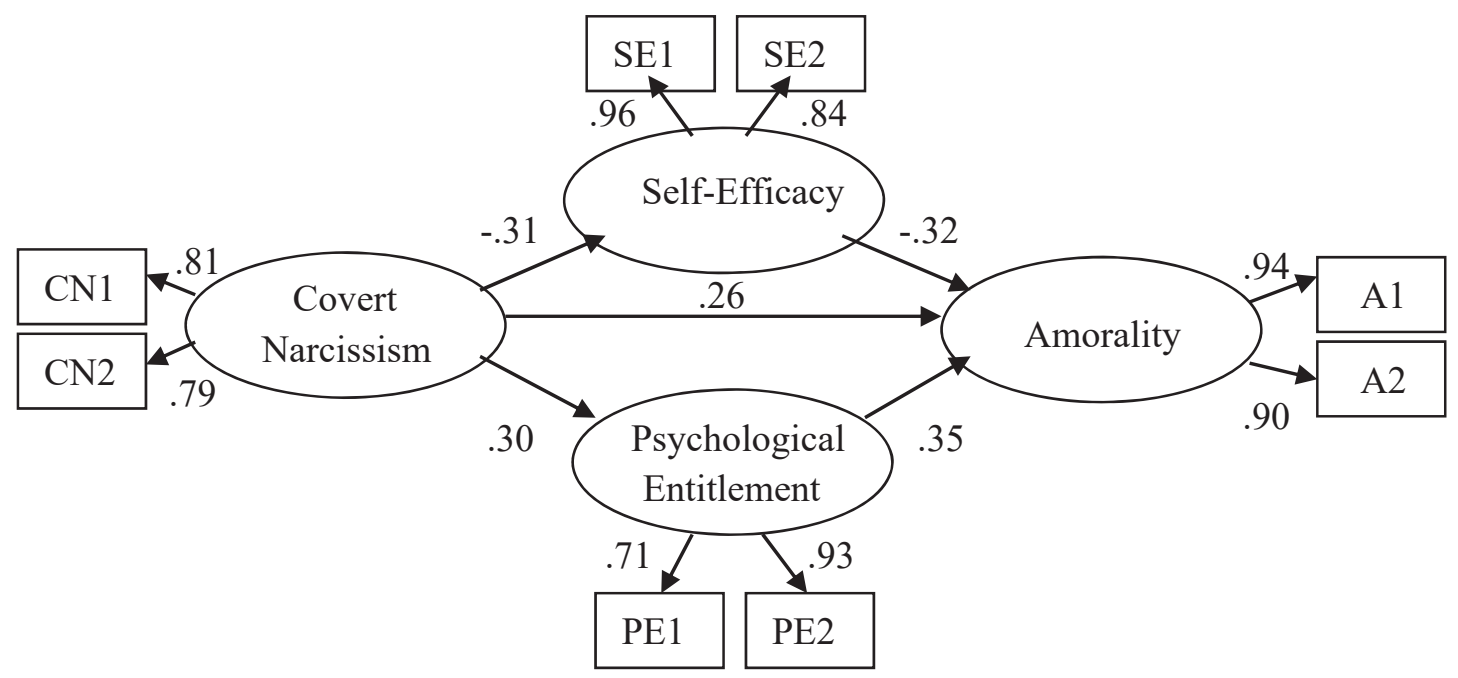


Note: Factor loadings are standardized. CN1-CN2 = two parcels of covert narcissism; SE1-SE2 $=$ two parcels of self-efficacy; PE1-PE2 = two parcels of psychological entitlement; A1-A2 = two parcels of amorality.

\section{DISCUSSION}

The current study examined the roles of both self-efficacy and entitlement as mediators between covert narcissism and amorality. Consistent with prior studies in which narcissism was negatively related to empathy (Watson, Grisham, Trotter, \& Biderman, 1984), and intimacy (Campbell et al., 2007) narcissism was found to be negatively correlated with amorality. Since much research related to narcissism has focused primarily on grandiose narcissism (Cain et al., 2008), there is little research to date investigating the mediating roles of self-efficacy and psychological entitlement between covert narcissism and amorality.

The current study found a negative relationship between covert narcissism and self-efficacy, consistent with previous research (Brookes, 2015) as well as an anticipated positive relationship between covert narcissism and psychological entitlement. It was also observed that self-efficacy and psychological entitlement did partially mediate the relationship between covert narcissism and higher amorality, supporting the study's predictions. These results are consistent with the anticipated negative association between self-efficacy and amorality as well as the positive relationship between psychological entitlement and amorality found in previous studies (Miller, 2015). With the mediators, the direct effect of covert narcissism on amorality was still significant, therefore self-efficacy and psychological entitlement both partially mediated the relationship between covert narcissism and amorality.

These findings underscore the need to recognize the different natures of overt narcissism and covert narcissism. In predicting amorality, the study found higher levels of overt narcissism to be negatively associated with self-efficacy, in contrast to the positive relationship between covert narcissism and selfefficacy (Campbell, et al., 2002; Grijalva \& Zhang, 2016). The study helps extend recent work done on narcissism and self-efficacy to include entitlement and the outcome of amorality. The inclusion of mediators helps provide a deeper and more nuanced understanding of the relationship between narcissism and amoral behavior. The work extends recent work done on narcissism and self-efficacy to include entitlement and the outcome of amorality. Practically speaking, organizations should recognize that individuals with higher levels of covert narcissism may be at an elevated risk for engaging in amoral behaviors to the detriment of the organization. Conversely, organizations may mitigate the risks associated with covert narcissists by utilizing selection procedures to avoid candidates with higher levels of covert narcissism. Organizations may also consider offering additional job training to increase selfefficacy, offsetting the effect of high covert narcissism. Additionally, organizations may benefit by evaluating reward systems to identify potentially amoral behaviors the systems may unintentionally promote, while simultaneously strengthening internal controls that could prevent or detect amoral behaviors when they occur.

As with any study, limitations are unavoidable. However, these limitations highlight opportunities for future research. A primary limitation of the current study is its cross-sectional nature. Future research should aim to employ time series data to assess directionality in the hypothesized relationships herein. In addition, the sample can only be generalizable to a limited extent as the participants were all college students; as such, generational aspects were unable to be explored. An extension to the current study would be to investigate the nature of these relationships across multiple generations. The model tested only includes the hypersensitive variety of narcissism. We theorized that self-efficacy has an opposite influence depending on the form of narcissism. Future studies should explore this complete model testing both grandiose and hypersensitive narcissism together. 


\section{REFERENCES}

Anderson, J. C., \& Gerbing, D. W. (1988). Structural equation modeling in practice: A review and recommended two-step approach. Psychological Bulletin, 103(3), 411-423.

Bandura, A. (1986). Social foundations of thought and action: A social cognitive theory. Englewood Cliffs, NJ: Prentice-Hall, Inc.

Bandura, A. (1997). Self-efficacy: The exercise of control. New York: Freeman.

Brookes, J. (2015). The effect of overt and covert narcissism on self-esteem and self-efficacy beyond selfesteem. Personality and Individual Differences, 85, 172-175.

Cain, N. M., Pincus, A. L., \& Ansell, E. B. (2008). Narcissism at the crossroads: Phenotypic description of pathological narcissism across clinical theory, social/personality psychology, and psychiatric diagnosis. Clinical psychology review, 28(4), 638-656.

Campbell, W. K., Rudich, E. A., \& Sedikides, C. (2002). Narcissism, self-esteem, and the positivity of self-views: Two portraits of self-love. Personality and Social Psychology Bulletin, 28(3), 358368.

Campbell, W. K., Bonacci, A. M., Shelton, J., Exline, J. J., \& Bushman, B. J. (2004). Psychological entitlement: Interpersonal consequences and validation of a self-report measure. Journal of Personality Assessment, 83(1), 29-45.

Campbell, W. K., Bosson, J. K., Goheen, T. W., Lakey, C. E., \& Kernis, M. H. (2007). Do narcissists dislike themselves "deep down inside"? Psychological Science, 18(3), 227-229.

Chen, G., Gully, S. M., \& Eden, D. (2001). Validation of a new general self-efficacy scale. Organizational Research Methods, 4(1), 62-83.

Chowning, K., \& Campbell, N. J. (2009). Development and validation of a measure of academic entitlement: Individual differences in students' externalized responsibility and entitled expectations. Journal of Educational Psychology, 101(4), 982.

Clark, M. A., Lelchook, A. M., \& Taylor, M. L. (2010). Beyond the Big Five: How narcissism, perfectionism, and dispositional affect relate to workaholism. Personality and Individual Differences, 48(7), 786-791.

Credo, K. R., Lanier, P. A., Matherne, C. F., \& Cox, S. S. (2016). Narcissism and entitlement in millennials: The mediating influence of community service self-efficacy on engagement. Personality and Individual Differences, 101, 192-195.

Dahling J.J., Whitaker B. G., \& Levy P. E. (2009). The development and validation of a new Machiavellianism scale. Journal of Management, 35(2) 219- 257.

Dickinson, K. A., \& Pincus, A. L. (2003). Interpersonal analysis of grandiose and vulnerable narcissism. Journal of personality disorders, 17(3), 188-207.

Gabbard, G. O. (2009). Transference and countertransference: Developments in the treatment of narcissistic personality disorder. Psychiatric Annals, 39(3), 129-136.

Giammarco, E. A., \& Vernon, P. A. (2014). Vengeance and the dark triad: The role of empathy and perspective taking in trait forgivingness. Personality and Individual Differences, 67, 23-29.

Grijalva, E., \& Zhang, L. (2016). Narcissism and Self-Insight A Review and Meta-Analysis of Narcissists' Self-Enhancement Tendencies. Personality and Social Psychology Bulletin, 42(1), 3 24.

Harvey, P., \& Harris, K. J. (2010). Frustration-based outcomes of entitlement and the influence of supervisor communication. Human Relations, 63(11), 1639-1660.

Hendin, H. M., \& Cheek, J. M. (1997). Assessing hypersensitive narcissism: A reexamination of Murray's Narcissism Scale. Journal of Research in Personality, 31(4), 588-599.

Hu, L. T., \& Bentler, P. M. (1999). Cutoff criteria for fit indexes in covariance structure analysis: Conventional criteria versus new alternatives. Structural Equation Modeling, 6(1), 1-55.

Jonason, P. K., \& Krause, L. (2013). The emotional deficits associated with the Dark Triad traits: Cognitive empathy, affective empathy, and alexithymia. Personality and Individual Differences, 55(5), 532-537. 
Judge, T. A., LePine, J. A., \& Rich, B. L. (2006). Loving yourself abundantly: relationship of the narcissistic personality to self-and other perceptions of workplace deviance, leadership, and task and contextual performance. Journal of Applied Psychology, 91(4), 762-776.

Lessard, J., Greenberger, E., Chen, C., \& Farruggia, S. (2011). Are youths' feelings of entitlement always "bad"?: Evidence for a distinction between exploitive and non-exploitive dimensions of entitlement. Journal of Adolescence, 34(3), 521-529.

Kong, F., Wang, X., \& Zhao, J. (2014). Dispositional mindfulness and life satisfaction: The role of core self-evaluations. Personality and Individual Differences, 56, 165-169.

Little, T. D., Cunningham, W. A., Shahar, G., \& Widaman, K. F. (2002). To parcel or not to parcel: Exploring the question, weighing the merits. Structural Equation Modeling, 9(2), 151-173.

Luchner, A. F., Houston, J. M., Walker, C., \& Houston, M. A. (2011). Exploring the relationship between two forms of narcissism and competitiveness. Personality and Individual Differences, 51(6), 779782.

Maynard, D. C., Brondolo, E. M., Connelly, C. E., \& Sauer, C. E. (2015). I'm too good for this job: Narcissism's role in the experience of overqualification. Applied Psychology, 64(1), 208-232.

Miller, B. K. (2015). Entitlement and conscientiousness in the prediction of organizational deviance. Personality and Individual Differences, 82, 114-119.

Miller, B. K., Smart, D. L., \& Rechner, P. L. (2015). Confirmatory factor analysis of the Machiavellian personality scale. Personality and Individual Differences, 82, 120-124.

Miller, J. D., Maples, J. L., Buffardi, L., Cai, H., Gentile, B., Kisbu-Sakarya, Y., ... Keith, W. (2015). Narcissism and United States' culture: The view from home and around the world. Journal of Personality and Social Psychology, 109(6), 1068-1089.

Paulhus, D. L., \& Williams, K. M. (2002). The dark triad of personality: Narcissism, Machiavellianism, and psychopathy. Journal of Research in Personality, 36(6), 556-563.

Rest, J. R., Narvaez, D., Bebeau, M. J., and Thoma, S. J., (1999). Postconventional moral thinking: A Neo-Kohlbergian approach. Mahwah, NJ: Lawrence Erlbaum Associates, Inc.

Shijiang, Z., Fang, W., Yan, X., Fengxiang, W., \& Xinting, Z. (2016). The fragile but bright facet in the Dark Gem: Narcissism positively predicts personal morality when individual's self-esteem is at low level. Personality and Individual Differences, 97, 272-276.

Tangney, J. P., Stuewig, J., \& Mashek, D. J. (2007). Moral Emotions and Moral Behavior. Annual Review of Psychology, 58, 345-372.

Twenge, J. M., Konrath, S., Foster, J. D., Campbell, W. K., \& Bushman, B. J. (2008). Egos inflating over time: A cross-temporal meta-analysis of the Narcissistic Personality Inventory. Journal of Personality, 76(4), 875-902.

Turnipseed, D. L., \& Cohen, S. R. (2015). Academic entitlement and socially aversive personalities: Does the Dark Triad predict academic entitlement? Personality and Individual Differences, 82, 72-75.

Wai, M., \& Tiliopoulos, N. (2012). The affective and cognitive empathic nature of the dark triad of personality. Personality and Individual Differences, 52(7), 794-799.

Watson, P. J., Grisham, S. O., Trotter, M. V., \& Biderman, M. D. (1984). Narcissism and empathy: Validity evidence for the Narcissistic Personality Inventory. Journal of Personality Assessment, 48(3), 301-305.

Wink, P. (1991). Two faces of narcissism. Journal of Personality and Social Psychology, 61(4), 590-597. 